\title{
Analysis of skin patch test results and metalloproteinase-2 levels in a patient with contact dermatitis
}

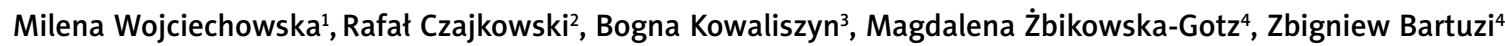 \\ ${ }^{1}$ Department of Public Health, Nicolaus Copernicus University in Torun, Ludwik Rydygier Medical College in Bydgoszcz, Poland \\ Head of the Department: Prof. Krzysztof Leksowski MD, PhD \\ ${ }^{2}$ Department of Dermatology, Sexually Transmitted Diseases and Immunodermatology, Nicolaus Copernicus University in Torun, \\ Ludwik Rydygier Medical College in Bydgoszcz, Poland \\ Head of the Department: Prof. Rafat Czajkowski MD, PhD \\ ${ }^{3}$ Department of Genetics and General Animal Breeding, University of Science and Technology, Bydgoszcz, Poland \\ Head of the Department: Prof. Sławomir Mroczkowski PhD \\ ${ }^{4}$ Department of Allergology, Clinical Immunology and Internal Diseases, Nicolaus Copernicus University in Torun, \\ Ludwik Rydygier Medical College in Bydgoszcz, Poland \\ Head of the Department: Prof. Zbigniew Bartuzi MD, PhD
}

Postep Derm Alergol 2015; XXXII (3): 154-161 DOI: 10.5114/pdia.2014.40979

\begin{abstract}
Introduction: The complex course of skin reactions that contact eczema involves is due in part to abnormalities of the extracellular matrix function. Proteins that degrade extracellular matrix components include metalloproteinases (MMP), which are divided into subcategories depending on the chemical structure and substrate specificity.

Aim: To analyse patch test results in contact dermatitis patients and to assess MMP-2 levels during skin lesion exacerbation and remission.

Material and methods: Fifty patients suffering from contact eczema were qualified to the study and 20 healthy volunteers as a control group. The study group patients had epidermal skin tests performed with the "European Standard" set. To assess the MMP-2 level in serum, venous blood was drawn, twice from study group patients - during contact dermatitis exacerbation and remission periods - and once from control group patients. Assessment of MMP-2 in serum was done with ELISA immunoassay. To verify the proposed hypotheses, parametric and nonparametric significance tests were used.

Results: Hands were the most frequent location of contact dermatitis. Nickel (II) sulphate was the most frequent sensitizing substance. Mean MMP-2 levels were statistically higher in the study group both in contact dermatitis exacerbation and remission periods than in the control group. There was no statistically significant difference between MMP-2 levels and skin patch test results.

Conclusions: Nickel is one of the most allergenic contact allergens in patients with contact dermatitis. Metalloproteinase- 2 is a good marker of contact dermatitis in various stages of the disease.
\end{abstract}

Key words: contact dermatitis, type 2 metalloproteinase, skin patch tests, contact allergy, pathomechanism.

\section{Introduction}

Contact dermatitis is a common dermatosis, and can have both allergic and non-allergic character. Many intrinsic and extrinsic factors (allergic and toxic substances, age, sex, ethnicity, genetic factors, comorbidities) influence the incidence of the disease. Non-allergic contact dermatitis (irritant eczema) is a local inflamma- tory skin reaction that is non-immune in nature and is caused by irritating action of the precipitating substance (acids, bases, water, soap, detergents, topical medications). Allergic contact dermatitis (ACD) is a skin inflammatory condition that occurs at the spot of contact with a low molecular weight substance or protein in an individual allergic to this substance. Pathogenesis of ACD is based on type IV immune reaction according to Gell and

Address for correspondence: Milena Wojciechowska MD, PhD, Department of Public Health, Ludwik Rydygier Medical College, Nicolaus Copernicus University, 16 Sandomierska St, 85-830 Bydgoszcz, Poland, phone: +48 5258554 08,

e-mail: milena.wojciechowska@cm.umk.pl

Received: 7.10.2013, accepted: 25.01.2014. 
Coombs - with the predominant role of specific lymphocytes $[1,2]$.

Skin patch tests are the "gold standard" in contact allergy diagnostics. They are a standardized attempt to provoke local skin reaction with ACD features (eczema reproduction) in strictly controlled conditions, as a reaction between the tested contact allergen and specifically sensitized lymphocytes. A positive result of skin patch testing proves the hypersensitivity of a subject to a hapten and also can identify the allergic cause of eczema. There are many known substances that can be contact allergens, with metals, preservatives, fragrances and pigments being the most common [1, 3, 4].

Imbalance between decay and synthesis of extracellular matrix (ECM) plays a role in specific pathologic processes in the skin and other organs. The amount of ECM components is dependent on the balance between degrading enzymes and tissue inhibitors of them [5]. The ECM is a multicomponent structure that fills the space between cells in various tissues. It forms scaffolding for tissues and storage of many growth factors and cytokines [6]. Collagen and non-collagen glycoproteins included in ECM participate in physiologic processes affecting cell adhesion, differentiation, migration, apoptosis and proliferation [1, 3, 7].

Metalloproteinases (MMPs) are a family of metaldependent $\left(\mathrm{Zn}^{2+}, \mathrm{Ca}^{2+}\right)$ endopeptidases that degrade proteins of extracellular matrix and basal membranes, which are a specialized form of ECM [8]. Metalloproteinases are synthesized in cells in a latent (inactive) form as preproenzymes and released into extracellular space as proenzymes [9]. Vascular-endothelial growth factor (VEGF), tumor necrosis factor- $\alpha$ (TNF- $\alpha$ ), interleukin-1 (IL-1), prostaglandins D2, E2, F2 $\alpha$ have a stimulating effect on cells to release MMPs. Inhibition of release of some MMPs by cells is mediated by e.g. steroid hormones and transforming growth factor- $\beta$ (TGF- $\beta$ ). Metalloproteinases can be activated both in extra- and intracellular environment, however, most MMPs are activated extracellularly. Metalloproteinases concentration and activity in tissues is regulated by many factors, e.g. on gene transcription, translation and proenzyme activation levels, by tissue inhibitors (TIMP), on a substrate specificity level, by environment $\mathrm{pH}$ and elevated temperature $[5,10]$.

Currently known MMPs are classified according to the chemical structure and substrate specificity of particular MMP. The chemical structure of MMPs includes domains that are common for the whole family and domains that are responsible for specific properties of an enzyme. Common features of all MMPs include a signal peptide, propeptide and catalytic domain. The hinge region between the C-terminal domain and catalytic domain is responsible for substrate specificity of an enzyme. It is composed of 15-65 amino acids and plays a significant role in stability of the enzymatic molecule structure $[5,9,10]$. In addition to ability to degrade ECM components (i.e. collagens, laminins, fibronectin, elastin, entactin, aggrecans, tenascin), ECM degrades also many other proteins and peptides, which are not ECM components, e.g. plasminogen, prolactin, $\alpha 1$-antichymotrypsin, TNF- $\alpha$. Metalloproteinases degrade numerous cell surface receptors, hydrolize molecules that are released from the cell membrane, thus activating and inactivating growth factors (e.g. insulin-like growth factor (IGF-1)), chemokines (e.g. CXC, platelet factor PF-4) and cytokines (e.g. TNF- $\alpha$ ) [11]. Inflammatory infiltration cells-monocytes, T-cells, leucocytes - are the main source of MMPs. However, MMP genes are expressed in keratinocytes, fibroblasts, macrophages, Langerhans cells and many other $[8,10]$.

Metalloproteinases is a gelatinase (type IV collagenase). Its molecular weight is $72 \mathrm{kDa}$ and it can degrade type I, IV, V, VII, X, XI, XIV collagen, gelatin, elastin, fibronectin, aggrecan, osteonectin, type 1 and 5 laminin, and type 1, 9, 13 MMPs [12]. Degradation of type IV collagen, the main component of the vascular basal membrane, by MMP-2 (and MMP-9) allows cell migration in morphogenesis and leucocyte migration to sites of inflammation. Metalloproteinase-2, like other MMPs, influences signalling between ECM and the cell. It participates in decorin (an ECM component that is a TGF- $\beta$ reservoir) degradation, causing release of TGF- $\beta$, which regulates expression of MMPs genes. By hydrolysis of a specific sequence of laminin-5, MMP-2 (and membrane type matrix metalloproteinase, MT1-MMP) stimulates endothelial cells migration, unveiling inaccessible cryptic sites that can transfer signals. Integrins (e.g. integrin $\alpha_{\mathrm{v}} \beta_{3}$ ), and MT1-MMP molecule, which participates in MMP-2 activation, anchor MMP-2 in the cell membrane [13].

Numerous MMPs, including MMP-2, participate in many physiologic processes, such as embryogenesis, angiogenesis, connective tissue regeneration. Metalloproteinases activity increases in many pathologic conditions, such as malignancies, autoimmune diseases, cardiovascular diseases, inflammatory diseases, skin diseases (dermatitis herpetiformis, pemphigus vulgaris, bullous pemphigoid, atopic dermatitis) and allergic diseases (bronchial asthma, urticaria, allergic rhinitis) $[5,14]$.

\section{Aim}

The aim of study was to analyse patch test results in contact dermatitis patients and to assess MMP-2 levels during skin lesion exacerbation and remission.

\section{Material and methods}

An ethical approval for our study was obtained from the ethics committee of the Nicolaus Copernicus University in Torun, Ludwik Rydygier Medical College in Bydgoszcz. 


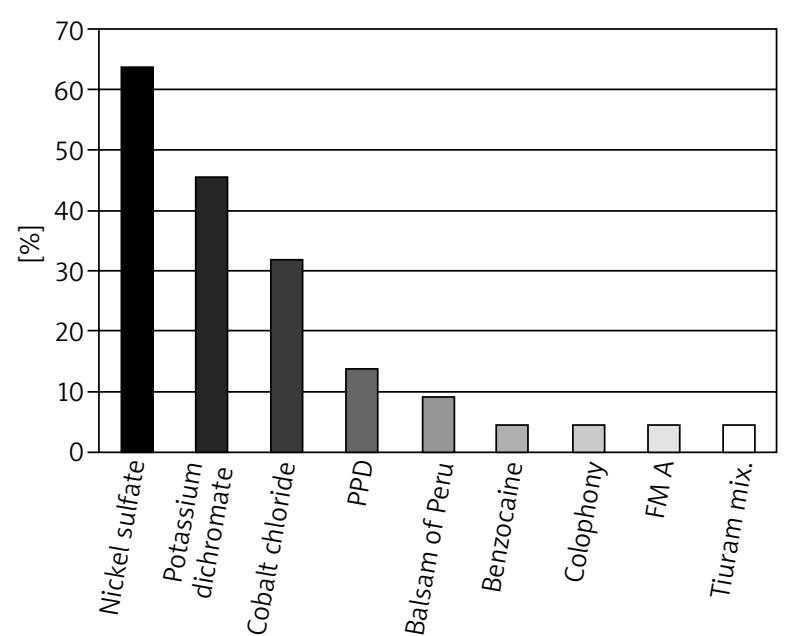

Figure 1. Frequency haptens $(n=50$; positive $n=22 /$ negative $n=28$ )

Fifty patients with contact dermatitis, aged 18-69 years (mean 38 years), participated in the study. Among them there were 27 (54\%) females and 23 (46\%) males. Diagnosis of contact dermatitis - clinical features: typical acute, subacute or chronic inflammatory skin lesions (with ACD lesions spreading to non-exposed sites) was the criterion of inclusion to the study group, providing absence of the following factors affecting study results: chronic and severe systemic diseases, drugs that might affect study results, including but not limited to systemic steroid drugs, administered within 2 weeks before study participation.

The control group consisted of 20 responders selected randomly, aged $20-58$ years (mean 34.3 years). There were 14 (70\%) females and 6 (30\%) males. Criteria of inclusion to the control group included the following: negative history of contact dermatitis, negative history of allergic diseases, no chronic, systemic illnesses, and no drugs being taken.

Medical history taking included gathering detailed information about current complaints, chronic diseases, past diseases and surgeries, as well as diseases that run in the family.

The study group patients had skin patch tests performed with haptens included in the "European Standard" set by Chemotechnique Diagnostics, Sweden. IQ Ultra chambers (Chemotechnique Diagnostics, Sweden) were used for skin patch testing. An appropriate amount of tested haptens (according to the manufacturer's guidelines, this was $20 \mu \mathrm{l}$ in case of petrolatum solution and $30 \mu \mathrm{l}$ in case of aqueous solution) was added to each chamber. Skin patch testing was conducted in accordance with skin patch testing recommendations by the International Contact Dermatitis Research Group (ICDRG). Chambers were applied onto the patient's back in the interscapular region. The tests were applied for $48 \mathrm{~h}$. Afterwards the tests were removed and the first reading was done. The second reading was done $72 \mathrm{~h}$ after the testing start.

To assess MMP-2 level in serum, venous blood was drawn, twice from study group patients - during contact dermatitis exacerbation and remission periods - and once from control group patients. Assessment of MMP-2 in serum was done with ELISA immunoassay with sets by R\&D Systems, Inc. (USA). The tests were conducted according to the manufacturer's instructions. The sensitivity of the method equals $0.047 \mathrm{ng} / \mathrm{ml}$. The reference range of MMP as reported by the manufacturer is 161$301 \mathrm{ng} / \mathrm{ml}$, and mean value is $199 \mathrm{ng} / \mathrm{ml}$.

\section{Statistical analysis}

To verify the proposed hypotheses, the following parametric and nonparametric significance tests were used: Shapiro-Wilk test for normality, Student's $t$ test, Mann-Whitney test, Wilcoxon test.

\section{Results}

In 24 patients from the study group, skin lesions in course of contact dermatitis were most frequently located on hands (46\%). In 12 (24\%) subjects, eczematous lesions were concomitantly located on hands, feet, neck and neckline. In 8 (16\%) subjects, facial eczema, and in 2 (4\%) back eczema was present.

Nickel (II) sulphate sensitized most often - 14 (28\%) subjects in the study group. The next most sensitizing substances were potassium dichromate - 10 (20\%) subjects and cobalt chloride -7 (14\%) subjects. Figure 1 presents the occurrence of allergy to tested haptens.

Table 1 presents the characteristics of the study subjects with skin patch test results and MMP-2 levels obtained from serum drawn during contact dermatitis exacerbation and remission.

Mean MMP-2 levels were found statistically higher in the study group than in the control group. This relationship was determined by comparing mean MMP-2 values in exacerbation and remission of skin lesions. In the contact dermatitis exacerbation stage, MMP-2 levels were statistically significantly higher in study group subjects: $n=50 ; 226.6 \pm 77.8 \mathrm{ng} / \mathrm{ml}$; range: $145.7-$ $477.5 \mathrm{ng} / \mathrm{ml}$ than in the control group: $n=20 ; 169.4$ $\pm 37.3 \mathrm{ng} / \mathrm{ml}$; range: $126.5-265.5 \mathrm{ng} / \mathrm{ml}$. In the skin lesion remission stage, MMP-2 levels were also statistically significantly higher in study group patients: $n=50 ; 197.2$ $\pm 55.0 \mathrm{ng} / \mathrm{ml}$; range $133.6-450.3 \mathrm{ng} / \mathrm{ml}$ than in the control group: $n=20 ; 169.4 \pm 37.3 \mathrm{ng} / \mathrm{ml}$; range: $126.5-265.5 \mathrm{ng} /$ $\mathrm{ml}$. Verification of significance of MMP-2 concentration changes in relation to disease phases had shown that mean MMP-2 values were statistically significantly higher in the contact dermatitis exacerbation phase compared to values found during skin lesion remission (Table 2).

In the group of patients with negative skin patch tests, men constituted $61 \%$ and women $39 \%$, where- 


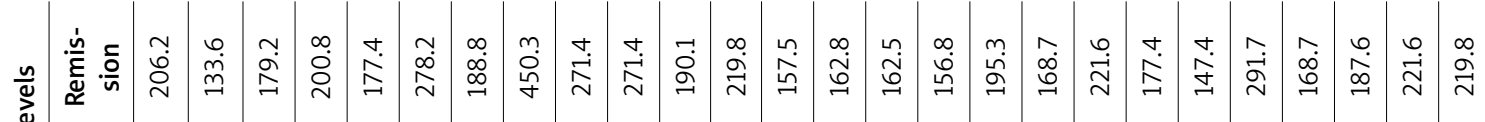

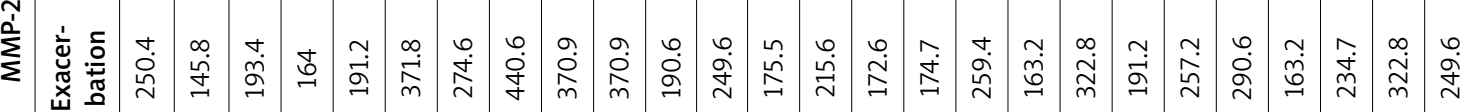
产

응

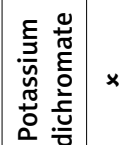

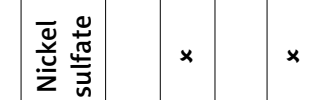

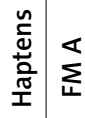

흥 $\frac{\overrightarrow{0}}{0}$

늘

它

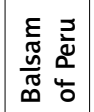

ఖँّ

$\frac{n}{c}$

总

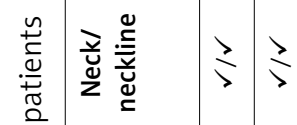

$\frac{1}{5} \frac{1}{5} \geq$

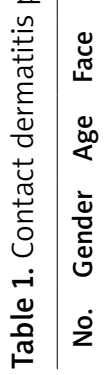

$>>>>>>>$

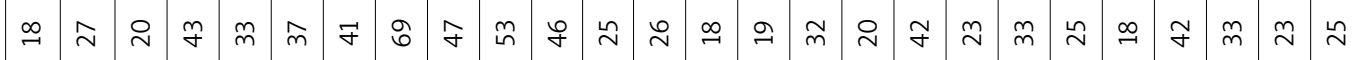

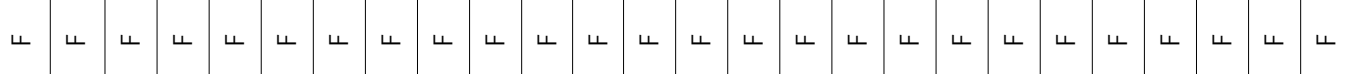

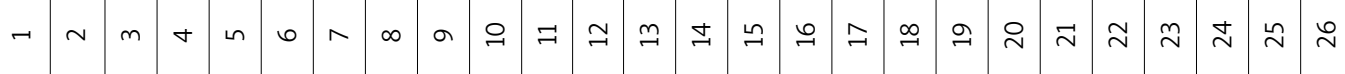




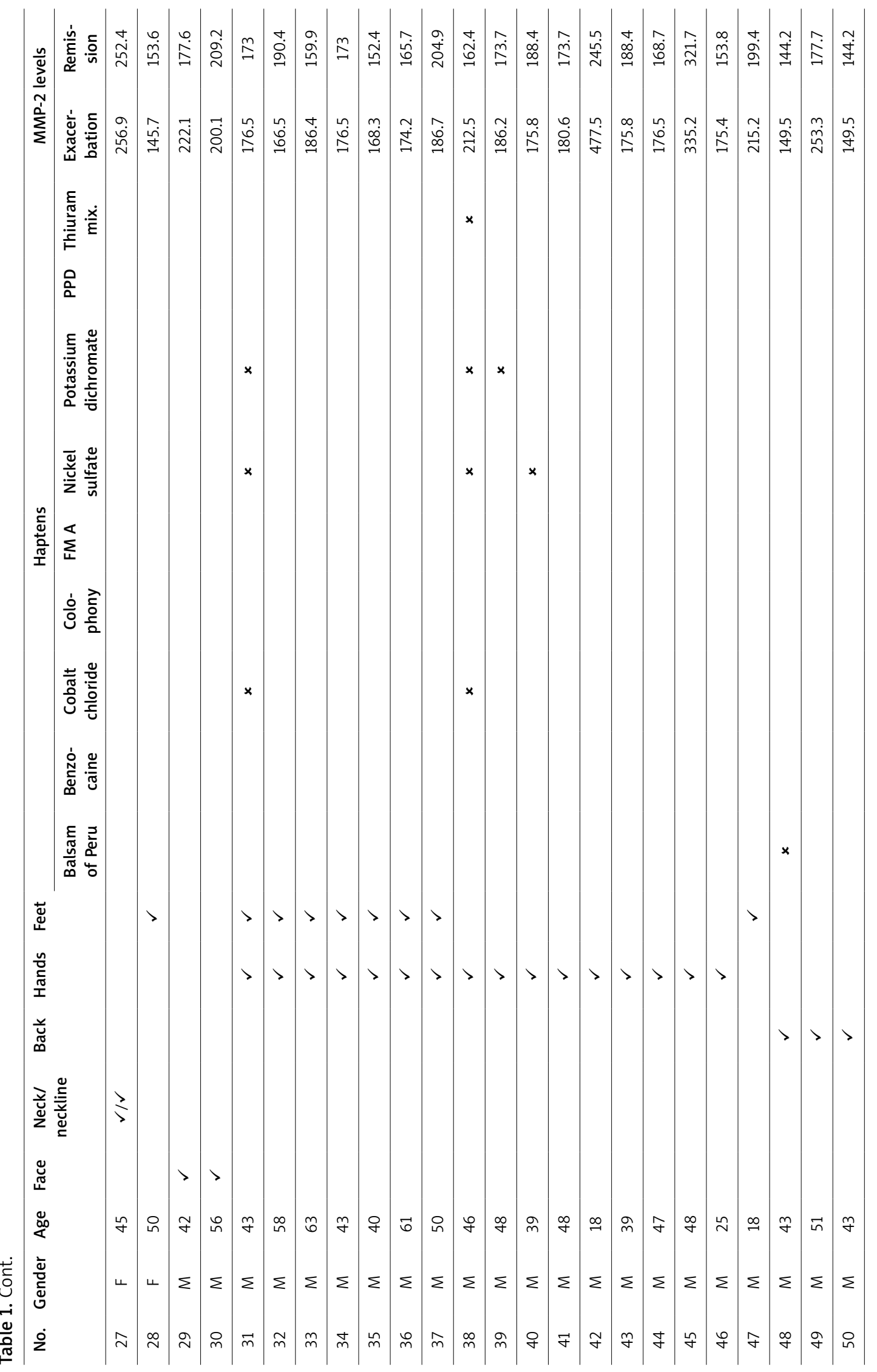


Table 2. Metalloproteinase-2 levels in contact dermatitis exacerbation/remission in contact dermatitis patients and in the control group. Mean differences of MMP-2 concentrations during contact eczema exacerbations and remissions

\begin{tabular}{|c|c|c|c|}
\hline \multirow[t]{2}{*}{ Parameter } & \multicolumn{2}{|c|}{ Contact dermatitis patients } & \multirow[t]{2}{*}{ Control group } \\
\hline & Contact dermatitis exacerbation & Contact dermatitis & \\
\hline Gender, $n(\%)$ & \multicolumn{2}{|c|}{ M 28 (56\%)/F 22 (44\%) } & M 14 (70\%)/F 6 (30\%) \\
\hline Age, mean \pm SD [years] & \multicolumn{2}{|c|}{$38.04 \pm 13.45$} & $34.30 \pm 10.87$ \\
\hline$n$ & 50 & 50 & 20 \\
\hline Mean & $226.6^{* * t+t}$ & $197.2^{\star t+t}$ & $169.4^{\star \star / \star}$ \\
\hline SD & 77.8 & 55.0 & 37.3 \\
\hline Median & $191.2^{\# \# \# \neq \neq \neq}$ & $178.5^{\# \# \neq \neq \neq \neq}$ & $160.9 \# \# \# / \# \#$ \\
\hline Min. & 145.7 & 133.6 & 126.5 \\
\hline Max. & 477.5 & 450.3 & 265.5 \\
\hline
\end{tabular}

t-Student test - ${ }^{*} p<0.05,{ }^{* *} p<0.01$; Mann-Whitney U test - ${ }^{\# \# p} p<0.01,{ }^{\# \#} p<0.001$; paired $t$-Student test $-{ }^{t+t} p<0.001$, Wilcoxon test - ${ }^{\text {㭋 }} p<0.001$.

as the group with a positive result was dominated by women $-77 \%$ of the respondents and $23 \%$ of the men. The observed differences were statistically significant $\left(\chi^{2}=7.22, p=0.00723\right.$, Fisher's exact test, $\left.p=0.0076\right)$. There was no statistically significant difference between MMP-2 levels and skin patch test results in the study group (Table 3).

\section{Discussion}

The contact dermatitis eruption location is usually related to the mode of exposure to the precipitating factor - a sensitizing and/or irritating substance. Hands were the most prevalent location of contact dermatitis among patients participating in the study. Other reports indicate that hands and wrists are the most common locations of contact dermatitis lesions, and patients with hand eczema are more often allergic to several allergens rather than to one allergen [15]. Similar observations were made in the presented study, in which hand eczema was present in patients allergic to metals, thiurams and Kathon CG. Hand eczema incidence is estimated to be 5.5 cases per 1000 persons per year, and risk factors include female sex, contact dermatitis, atopic dermatitis and occupational exposure [15].

Among the wide range of substances with contact sensitizing properties, metals are one of the most potent. In the ESSCA study (European Surveillance System of Contact Allergies), nickel sensitized 20\%, cobalt 7\%, and chromium $4 \%$ of the European population [16]. Similar percentage of persons allergic to metals was found in the United States [17]. In a performed study, nickel sulphate, potassium dichromate and cobalt chloride were the most sensitizing. In a multicenter European study, in which 19,793 subjects underwent skin patch testing, nickel sensitized $19.7 \%$ patients from Central Europe and 24.4\% patients from Southern Europe [16]. In 10 (20\%) subjects, allergy to potassium dichromate was found. The proportion of persons allergic to chromium in the
Table 3. Metalloproteinase-2 levels and skin patch test results in contact dermatitis patients

\begin{tabular}{|c|c|c|}
\hline Parameter & Patch test - & Patch test + \\
\hline Gender, $n(\%)^{\star \star}$ & F 11 (39\%)/M 17 (61\%) & F 17 (77\%)/M 5 (23\%) \\
\hline $\begin{array}{l}\text { Age, mean } \pm \text { SD } \\
\text { [years] }\end{array}$ & $40.1 \pm 13.1$ & $35.5 \pm 13.8$ \\
\hline$n$ & 28 & 22 \\
\hline \multicolumn{3}{|c|}{ MMP-2 levels - contact dermatitis exacerbation } \\
\hline Mean $\pm S D$ & $227.8 \pm 76.6$ & $225.1 \pm 81.1$ \\
\hline Median & 195.6 & 190.9 \\
\hline Min. & 145.7 & 145.8 \\
\hline Max. & 477.5 & 440.6 \\
\hline \multicolumn{3}{|c|}{ MMP-2 levels - contact dermatitis remission } \\
\hline Mean & $196.2 \pm 45.3$ & $198.5 \pm 66.4$ \\
\hline Median & 182.6 & 178.3 \\
\hline Min. & 144.2 & 133.6 \\
\hline Max. & 321.7 & 450.3 \\
\hline
\end{tabular}

${ }^{* *} \chi^{2}$ test $p<0.001$, Fisher's exact test $p<0.001$.

United Kingdom is between 1.3 and 9.1\% [16]. In Spain, in 1092 subjects, who had skin patch testing with the standard set, chromium allergy was found in 82 (7.5\%) patients [18]. Chromium was the most frequent contact allergen in Poland, towards the end of the last century (1970-1995). Chromium allergy is more common in males than in females, as a result of exposure (construction industry - cement). Now, the frequency of allergy to chrome among construction workers decreases because of improved working conditions [19]. In males, chromium allergy often accompanies cobalt allergy. Cobalt allergy is rarely an "isolated" allergy, i.e. without concomitant hypersensitivity to chromium and/or nickel [20]. Cobalt allergy was found in 7 (14\%) participants of the study, and in all cases this allergy coexisted with an allergy to 
either chromium (2 subjects), nickel (1 subject) or both chromium and nickel (4 subjects).

In $3(6 \%)$ subjects, allergy to para-phenylenediamine (PPD), a potent allergenic aromatic amine, was found. The PPD allergy among contact dermatitis patients reaches $4.3 \%$ in Asia, 4\% in Europe and 6.2\% in the United Stated [21].

Allergy to fragrances occurs most often due to their presence in cosmetics, less so in drugs and food. Hypersensitivity to fragrances is estimated to affect $1-6 \%$ of the general population. In the EC countries, allergy to fragrances reaches $8-10 \%$ of contact dermatitis patients [22]. In 2 (4\%) study patients, allergy to balsam of Peru, and in 1 (2\%) allergy to perfume mix A was found. Coniferyl benzoate is the main allergen of the balsam of Peru. The remaining ones, i.e. cinnamic aldehyde, eugenol or isoeugenol, are included in the perfume mix.

Single patients in the presented study were allergic to colophony, benzocaine and thiuram mix. Colophony is a mixture of approximately 100 chemical compounds, $95 \%$ of which is abietic acid, the main allergen of rosin. Bajaj et al. [23] estimated the prevalence of colophony allergy to be $5.7 \%$ among 590 patients with a positive skin patch test. Benzocaine is chemically an ester of $p$-aminobenzoic acid and ethanol, and is used as a local anesthetic. Allergic contact dermatitis caused by benzocaine was found in patients who used condoms containing benzocaine for ejaculation delay [24]. Vu and Lockey [25] reported anaphylactic shock after use of benzocaine as a local anesthetic during a cosmetic procedure. Thiurams are potent allergens, used mainly to accelerate vulcanization of various types of gum. Hypersensitivity to thiuram mix varies between 1.7 and $2.4 \%[15,16]$.

Pathogenesis of contact dermatitis is very complex. The mechanism of clinical symptoms is different depending on allergic or non-allergic background of dermatitis. Pathogenesis of non-allergic contact dermatitis follows a non-immune path. Allergic contact dermatitis is a chain of complex processes of the immune system with response to chemical substances present in the environment (haptens) divided into two phases: induction (primary, afferent) and effector (secondary, efferent). A typical histologic picture of ACD includes edema (spongiosis), spinous layer hyperplasia (acanthosis), incomplete keratosis (parakeratosis) and presence of lymphocytic infiltrates [26]. Despite the role of the individual MMPs in skin inflammatory processes has been identified, the reports on contribution of MMPs in contact dermatitis pathogenesis are scarce. Our previous study [27] is one of few reports on concentration of selected MMPs in contact eczema. We showed that MMP-2 and MMP-9 levels are higher in the period of exacerbation of contact dermatitis than in the remission phase.

Gelatinases degrade extracellular matrix components; among their substrates are various types of collagen. ACD involves deformation of cutis and epidermis texture as well as remodeling of collagen fibre streaks.
An increased amount of type I and type III collagen has been demonstrated in the skin affected by chronic contact dermatitis [28]. Fibroblasts are among potential targets of MMP-2. In course of ACD these cells show increased proliferation with concomitant overexpression of MMP-2 activity regardless of the cell number [29]. Histological and clinical presentation of ACD is different depending on the disease stage: acute or chronic. The presented study has demonstrated that MMP-2 concentrations are statistically significantly higher in the exacerbation phase than in the remission phase of contact dermatitis. In both phases of $A C D$, expression and distribution of ECM components and activity of degrading enzymes are different. Metalloproteinases participate in detachment of Langerhans cells residing in suprabasal epidermis layers from adjacent keratinocytes and in passage of these through the basal membrane of the cutis-epidermis border [30].

There was no statistically significant difference between MMP-2 levels and skin patch test results in the current study. In the study by Giannelli et al. [31], a weak expression of MMP-2 in the basal epidermis layer was found in skin biopsy specimens from healthy volunteers. In specimens from patients with positive skin patch tests, the researchers observed an increased expression of MMP-2, and the excessive MMP-2 levels were found in epidermis, connective tissue and inflammatory infiltrations, but first of all in the extracellular space, especially around blister edges. These results suggest that MMP-2 participates in blistering lesion pathogenesis, and that ACD eruptions include blisters. Giannelli et al. found no difference of MMP-2 concentrations in ACD patients and the control group. However, the results of the current study are different. Metalloproteinases levels were statistically significantly higher in study group patients than in control group responders. This finding suggests a role of MMP-2 in the contact dermatitis pathomechanism.

\section{Conclusions}

Our study demonstrated that nickel is one of the most important contact allergens. However, we often found also chrome allergy. It is one of the few reports about the role of selected MMPs in the contact dermatitis pathomechanism. Despite increased concentrations of the studied marker were related to the disease process, further studies in the field are required.

\section{Acknowledgments}

The study funded by the "Scholarship for doctoral students - Integrated Development Regional Operational Programme".

\section{Conflict of interest}

The authors declare no conflict of interest. 


\section{References}

1. Śpiewak R. Contact allergy - diagnosing and treatment. Alergia Astma Immunol 2007; 12: 109-26.

2. Rutkowski K, Sowa P, Rutkowska-Talipska J, et al. Allergic diseases: the price of civilisational progress. Postep Derm Alergol 2014; 31: 77-83.

3. Żmudzińska M, Czarnecka-Operacz M. Development of contact allergy diagnostics. Postep Derm Alergol 2005; 22: 179-82.

4. Reduta T, Bacharewicz J, Pawłoś A. Patch test results in patients with allergic contact dermatitis in the Podlasie region. Postep Derm Alergol 2013; 30: 350-7.

5. Dziankowska-Bartkowiak B, Waszczykowska E, Żebrowska A. The role of metalloproteinases and their inhibitors in the patomechanism of skin diseases. Alergia Astma Immunol 2004; 9: 71-9.

6. Sivakumar P, Czirok A, Rongish BJ, et al. New insight into extracellular matrix assembly and reorganization from dynamic imaging of extracellular matrixproteins in living osteoblasts. J Cell Sci 2006; 119: 1350-60.

7. Hynes RO. The extracellular matrix: not just pretty fibrils. Science 2009; 326: 1216-9.

8. Hrabec E, Naduk J, Stręk M, et al. Type IV collagenases (MMP-2 and MMP-9) and their substrates: intracellular proteins, hormones, cytokines, chemokines and their receptors. Adv Biochem 2007; 53: 37-45.

9. Rosenblum G, Meroueh S, Toth M, et al. Molecular structures and dynamics of the stepwise activation mechanism of a matrix metalloproteinase zymogen: challenging the cysteine switch dogma. J Am Chem Soc 2007; 129: 13566-74.

10. Lipka D, Boratyński J. Metalloproteinases. Structure and function. Adv Hyg Exp Med 2008; 62: 328-36.

11. Przybyłowska K, Błasiak J. Matrix metalloproteinases and their role in cancer progression. Adv Biochem 2001; 47: 212-22.

12. Dziankowska-Bartkowiak B, Żebrowska A, Joss-Wichman E, et al. Serum levels of metalloproteinases-2 and -9 (MMP-2, MMP-9) correlation with their expression in skin lesions in systemic sclerosis - the preliminary examination. Postep Derm Alergol 2007; 24: 73-81.

13. Van Hinsbergh VW, Engelse MA, Quax PH. Pericellular proteases in angiogenesis and vasculogenesis. Arterioscler Thromb Vasc Biol 2006; 26: 716-28.

14. Kuźmiński A, Przybyszewski M, Graczyk M, et al. The role of extracellular matrix metalloproteinases and their inhibitors in allergic diseases. Postep Derm Alergol 2012; 29: 384-9.

15. Thyssen JP, Johansen JD, Linneberg A, et al. The epidemiology of hand eczema in the general population - prevalence and main findings. Contact Dermatitis 2010; 62: 75-87.

16. The ESSCA Writing Group. The European Surveillance System of Contact Allergies (ESSCA): results of the patch testing the standard series. J Eur Acad Dermatol Venerol 2008; 22: 174-81.

17. Nguyen SH, Dang TP, MacPherson C, et al. Prevalence of patch test results from 1970 to 2002 in a multi-centre population in North America (NACDG). Contact Dermatitis 2008; 58: 101-6.

18. Bordel-Gòmez MT, Miranda-Romero A, Castrodeza-Sanz J. Isolated and concurrent prevalence of sensitization to transition metals in a Spanish population. Eur Acad Dermatol Venerol 2008; 22: 1452-7.

19. Rudzki E. Evolution of contact allergy in Poland (from CMEA to UE). Alergia Astma Immunol 2005; 10: 53-7.
20. Lisi P, Bruneli L, Stingeni L, et al. Co-sensitivity between cobalt and other transition metals. Contact Dermatitis 2003; 48: 172-3.

21. McFadden JP, Yeo L, White JL. Clinical and experimental aspects of allergic contact dermatitis to para-phenylenediamine. Clin Dermatol 2011; 29: 316-24.

22. Kieć-Świerczyńska M. Allergy to cosmetics. Contact allergy. Mediton, Lodz 2005; 43-67.

23. Bajaj AK, Saraswat A, Mukhija G. Patch testing experience with 1000 patients. Indian J Dermatol Venerol Leprol 2007; 73: 313-8.

24. Muratore L, Calogiuri G, Foti C, et al. Contact allergy to benzocaine in a condom. Contact Dermatitis 2008; 59: 173-4.

25. Vu AT, Lockey RF. Benzocaine anaphylaxis. J Allergy Clin Immunol 2006; 118: 534-5.

26. Alsaad KO, Ghazarian D. My approach to superficial inflammatory dermatoses. J Clin Pathol 2005; 58: 1233-41.

27. Wojciechowska M, Żbikowska-Gotz M, Czajkowski R, et al. Serum concentrations of metalloproteinase 2, metalloproteinase 9 and granzyme B in contact eczema patients. Postep Derm Alergol 2013; 30: 73-6.

28. Hirota A, Ebihara T, Kusubata M, et al. Collagen of chronically inflamed skin is over-modified and upregulates secretion of matrix metalloproteinase 2 and matrix-degrading enzymes by endothelial cells and fibroblasts. J Investig Dermatol 2003; 121: 1317-25.

29. Khorramizadeh M, Afalak R, Pezeshki M, et al. Dermal wound fibroblasts and matrix metalloproteinases (MMPs): their possible role in allergic contact dermatitis. Iran J Allerg Asthmas Immunol 2004; 3: 7-11.

30. Steinman RM. The dendritic cell system and its role in immunogenicity. Ann Rev Immunol 1991; 9: 271-96.

31. Giannelli G, Foti C, Marinosci F, et al. Gelatinase expression at positive test reactions. Contact Dermatitis 2002; 46: 280-5. 